\title{
MINAT REMAJA DITINJAU DARI TES MINAT ROTHWELL MILLER INTEREST BLANK (RMIB) DI LEMBAGA KESEJAHTERAAN SOSIAL ANAK (LKSA) KOTA PALANGKA RAYA
}

\author{
Meylani Safar Rini ${ }^{1}$, Ihsan $\mathrm{Mz}^{2}$, Desi Erawati ${ }^{3}$, \\ Program Studi Bimbingan Konseling Islam, Fakultas Ushuluddin, Adab dan Dakwah, \\ Institut Agama Islam Negeri Palangka Raya \\ 2ihsan.mz@iain-palangkaraya.ac.id
}

\begin{abstract}
ABSTRAK
Generasi milenial sekarang cenderung kesulitan menentukan minat atau karirnya di masa depan. Oleh sebab itu penelitian ini mengurai tentang minat remaja ditinjau dari tes Rothwell Miller Interest Blank atau disingkat RMIB. Remaja tidak akan melakukan suatu aktivitas yang mereka senangi jika mereka tidak menyadari kebutuhan terhadap minatnya. Jenis penelitian ini menggunakan penelitian kualitatif deskriptif. Informan penelitian ini adalah remaja berusia 15-18 tahun, berjumlah sembilan orang di Lembaga Kesejahteraan Sosial Anak (LKSA) Al-Amin Kota Palangka Raya. Pengumpulan data dilakukan dengan tes minat RMIB, wawancara, observasi, yang dianalisis menggunakan teknik triangulasi sumber. Hasil penelitian yang ditemukan di lapangan menunjukkan bahwa tes RMIB remaja di LKSA Al-Amin memiliki berbagai minat diantaranya social service, medical, mechanical, dan practical. Terdapat empat orang yang memiliki kecenderungan pada minat social service, dua orang cenderung pada medical, dua orang mechanical dan terdapat satu orang yang mempunyai minat pada bidang practical. Penelitian ini juga mengungkap adanya pengaruh motivasi internal dan eksternal yang mendorong remaja di LKSA Al-Amin untuk menguatkan minat yang mereka miliki. Khusus pada motivasi eksternal, motif sosial dan emosional mempunyai peran yang signifikan dalam menumbuhkan minat pada remaja di LKSA Al-Amin.
\end{abstract}

Kata Kunci: LKSA; Minat; Remaja; Tes Rothwell Miller Interest Blank (RMIB).

\begin{abstract}
Millennials today are tend to determine their future interests or careers. Therefore, this study describes about adolescents' interest from the Rothwell Miller Interest Blank test (RMIB). Adolescents will not do actvity based on their will once they are not aware of their interests. This type of research used was descriptive qualitative. The respondent of this study were nine teenagers aged 15-18 years at the Al-Amin Child Welfare Institution (LKSA) Palangka Raya City. Data was collected by using the RMIB interest test, interviews, and observations, which analyzed using triangulation techniques. This research showed that the reasult of adolescents' RMIB test at LKSA Al-Amin had various interests including social service, medical, mechanical, and practical. Found four adolescents who tend to have interest in social services, two adolescents who tend to medical field, two adolescents were tend to mechanical and there was one adolescent with practical interest. This study also reveals the influence of internal and external motivations that encouraged adolescents at LKSA Al-Amin to strengthen their interests. Specifically on external motivation, social and emotional motives had significant role in growing interest in adolescents in LKSA Al-Amin.
\end{abstract}

Keywords: Adolescent; Interest; LKSA; RMIB

Dipublikasikan Oleh :

UPT Publikasi dan Pengelolaan Jurnal

Universitas Islam Kalimantan Muhammad Arsyad Al-Banjari Banjarmasin 


\section{PENDAHULUAN}

Minat berperan penting bagi setiap individu dalam kehidupannya karena minat berpengaruh besar atas segala perilaku dan sikap seorang individu. Minat juga menjadi faktor yang signifikan dalam memotivasi seseorang. Menurut Kamus Besar Bahasa Indonesia (KBBI), minat adalah suatu kecenderungan hati yang tinggi terhadap sesuatu, yang berarti pula suatu gairah atau keinginan (Kemdikbud, t.t.). Dalam bahasa Inggris, minat disebut dengan "Interest" atau "Passion". Interest diartikan sebagai perasaan ingin memperhatikan dan penasaran akan sesuatu hal, sedangkan Passion diartikan sebagai gairah atau seseuatu perasaan yang sangat antusias terhadap sesuatu hal (Sefrina, 2013).

Minat ialah kesadaran yang ada pada seseorang menimbulkan objek tertentu yang disenangi dan melahirkan suatu perhatian yang tinggi terhadap objek tersebut. Selain itu, minat merupakan kemampuan memberikan stimulus untuk memperhatikan aktivitas yang ingin dilakukan ini didapatkan dari pengalaman yang sebenarnya (Sriastuti \& Lasmawan, 2014).

Minat akan berkembang seiring berjalannya waktu, dari fase anak-anak, fase remaja hingga dewasa. Masa anak-anak dimulai ketika melewati masa bayi yang penuh ketergantungan. Masa ini kira-kira berada pada rentang usia dua sampai sebelas tahun untuk wanita dan 12 tahun untuk pria. Pada fase ini, terjadi beberapa perubahan yang relevan, baik secara fisik maupun psikologis (Ajhuri, 2019; Hurlock, 1980).

Masa pertengahan dan akhir anak-anak bisa dilihat dengan masuknya anak-anak ke sekolah dasar kelas satu. Bagi beberapa anak, terjadi perubahan besar dalam pola kehidupan. Hal ini dikarenakan memasuki kelas adalah peristiwa penting bagi anak-anak yang dapat mengakibatkan perubahan sikap, nilai-nilai dan perilaku. Ketika anak-anak memasuki sekolah dasar, kemampuan kognitif anak akan mengalami perkembangan yang cepat. Masuk sekolah berarti dunia dan minat anak-anak mulai tumbuh. Adanya minat ini akan meningkatkan wawasan tentang manusia dan benda-benda yang sebelumnya kurang dipahami oleh anak-anak. Saat dalam kondisi yang normal, pikiran anakanak akan bertambah dan berkembang seiring bertambahnya waktu (Desmita, 2013).

Seiring bertambahnya usia anak, minat akan meningkat dan dapat mempengaruhi hubungannya dengan teman sebaya. Hal ini dikarenakan anak hanya peduli dengan teman yang memiliki kesamaan hobi. Berbagai macam minat akan membahagiakan individu, meskipun kebutuhan ini mungkin tidak langsung terlihat oleh orang dewasa. Tetapi semakin sering minat diekspresikan dalam berbagai kegiatan, maka akan semakin kuat minat tersebut. Sebaliknya, minat akan melemah jika tidak tersalurkan.

Menurut Vygotsky (dalam Adamson dkk., 2010), jika kebutuhan individu tidak diketahui, di mana hal tersebut efektif untuk digunakan sebagai insentif ketika anak berperilaku, maka perkembangan dari satu tahap ke tahap yang lain tidak akan pernah dipahami. Begitu juga dengan remaja yang pada masa ini ditandai sebagai individu yang menginginkan sesuatu dan sedang mencari sesuatu. Jika remaja tidak mengetahui tentang kebututuhannya, maka remaja tidak akan memahami tugas-tugas perkembangannya.

Masa remaja merupakan masa transisi dari masa anak-anak menuju masa dewasa, yaitu antara usia 10 sampai 24 tahun. Di masa inilah seseorang akan mencari jati diri untuk membentuk karakter, kepribadian, seperti pengalaman baru maupun teman baru (Santrock, 2006). Secara umum, berbagai rentang usia remaja ini biasanya dibedakan menjadi tiga, yaitu masa remaja awal pada usia 12-15 tahun, remaja masa pertengahan antara usia 15-18 tahun, dan remaja akhir rentang usia 18-21 tahun (Desmita, 2013).

Tugas perkembangan pada fase remaja adalah sebagai berikut; a) menerima fisik dan keanekaragamannya sendiri, b) mencapai kemandirian emosional dari orang tua, c) mengembangkan keterampilan komunikasi interpersonal dan belajar untuk bergaul dengan teman sebaya atau orang lain baik secara individu maupun kelompok, d) menemukan manusia yang digunakan sebagai identitas mereka, e) memiliki kepercayaan dalam kemampuannya sendiri, memperkuat kontrol diri (kemampuan kontrol diri) atau skala nilai dasar, prinsip-prinsip atau filosofi kehidupan, dan f) mampu meninggalkan reaksi dan penyesuaian diri (sikap/perilaku) kekanak-kanakan (Akmila dkk., 2019).

Remaja yang dapat melakukan tugas perkembangan dengan baik tentu saja akan dapat melalui masa remaja dengan lancar. Jika tugas perkembangan dapat berhasil diselesaikan, akan membawa kebahagiaan dan kesuksesan dalam menyelesaikan tugas berikutnya (Rahmawati \& Rahmah, 2016).

Penelitian Diananda (2019) menunjukkan bahwa setiap rentang usia memiliki karakteristik khusus yang membedakannya dari fase 
pertumbuhan lainnya. Demikian pula, pada usia remaja, memiliki karakteristik yang berbeda dari fase kanak-kanak dan dewasa. Selain itu, setiap fase memiliki kondisi dan tuntutan yang khas untuk setiap individu.

Seiring berjalannya waktu, ketika remaja berada di sekolah, kemampuan kognitif akan berkembang pesat. Karena dengan sekolah berarti dunia dan juga kepentingan anak-anak akan mengalami kemajuan dan pengetahuannya akan tersebar luas. Dalam keadaan normal, pikiran anak-anak usia sekolah akan berkembang secara bertahap dan ingatan anak-anak akan lebih kuat (Desmita, 2013).

Dalam konteks ajaran agama Islam, salah satu visi sentral Nabi Muhammad Saw. adalah peningkatan sumber daya manusia yang benarbenar utuh, tidak hanya secara fisik tetapi juga dalam pikiran. Peningkatan kualitas manusia dilakukan selaras dengan misi kenabian, yaitu untuk mendidik manusia, menuntun mereka dengan cara Allah Swt. Nabi Muhammad Saw. diutus untuk mengembangkan kualitas kehidupan manusia, menyucikan moral, dan membekali mereka dengan bekal-bekal untuk menghadapi kehidupan di dunia dan di akhirat kelak (Samsudin, 2015).

Lembaga Kesejahteraan Sosial Anak (LKSA) yang terdapat di Kota Palangka Raya berjumlah 33 lembaga. Berdasarkan data yang diperoleh dari Dinas Sosial Palangka Raya, LKSA Al-Amin adalah salah satu lembaga yang mendapat akreditasi "A" (Dinas Sosial, t.t.). Anak-anak yang di asuh di LKSA biasanya berasal dari keluarga yang kurang mampu, anak yatim piatu, anak terlantar, dan lain-lain. Selain itu, latar belakang pemilihan lokasi di LKSA AlAmin adalah adanya indikasi bahwa remaja di Al-Amin belum mengetahui secara keseluruhan tentang minat yang dimiliki. Tujuan penelitian ini adalah memberikan panduan kepada anak asuh LKSA agar ketika meninggalkan atau keluar dari LKSA, mereka akan mendapatkan bekal untuk masa depan, diantaranya melalui upaya identifikasi minat yang dimiliki oleh anak asuh LKSA Al-Amin.

\section{METODE}

Jenis penelitian ini menggunakan penelitian deskriptif dengan pendekatan kualitatif, desain yang digunakan pada penelitian adalah studi kasus. Pendekatan kualitatif ini menggunakan situasi sosial tertentu dengan menggambarkan kenyataan dengan benar, dibantu oleh kata-kata berdasarkan teknik pengumpulan data dan analisis data yang relevan yang diperoleh dari situasi alam. Penelitian ini menggunakan studi deskriptif kualitatif bertujuan untuk mengetahui minat remaja di LKSA AlAmin Kota Palangka Raya. Jenis penelitian ini adalah prosedur pemecahan masalah yang diselidiki dengan menggambarkan keadaan subjek atau objek penelitian (Sugiyono, 2008).

Adapun teknik pengumpulan data yang dilakukan adalah menggunakan triangulasi teknik melalui alat tes minat dan bakat RMIB, observasi dan wawancara. Tes RMIB dikembangkan oleh Rothwell pada tahun 1947, kemudian di perbaharui oleh Kanneth Miller tahun 1950, tes ini merupakan bentuk test battery, yang mana klien mengerjakan tes dalam batas waktu tertentu. Pada tes ini mengngkapkan reaksi seseorang terhadap berbagai situasi yang secara keseluruhan akan mencerminkan minatnya. Ungkapan minat yang disampaikan RMIB biasanya lebih mencerminkan kondisi yang sesungguhnya, dibanding apa yang diungkapkan secara langsung (Yuliandari, 2020). Alat tes RMIB bertujuan untuk mengetahui minat remaja di LKSA Al-Amin.

Aspek yang diamati pada penelitian ini ialah kondisi fisik, penampilan subjek, dan perilakunya ketika mengikuti wawancara. Pada wawancara, diberikan beberapa pertanyaan terkait perasaan senang, perhatian, dan ketertarikan terhadap sesuatu yang diminati informan (subjek penelitian). Kemudian observasi dan wawancara berfungsi untuk memperdalam informasi yang diperoleh dari informan. Subjek pada penelitian ini ialah remaja berusia 15 sampai 18 tahun, pada usia ini individu menginginkan dan mencari-cari sesatu merasa sunyi dan tidak dapat dimengerti oleh orang lain.

\section{HASIL DAN PEMBAHASAN}

Responden pada penelitian ini berjumlah sembilan orang yang berjenis kelamin laki-laki (Lk) dan perempuan (Pr). Pada Tabel 1 disajikan hasil tes minat RMIB remaja di LKSA Al-Amin Kota Palangka Raya.

Responden FH dan FJ memiliki minat yang sama pada bidang medical. FH dan FJ sudah melakukan usaha untuk memperdalam minatnya tersebut. Saat ini FH sedang berjuang untuk mendaftar dan melakukan tes agar dapat kuliah di Politeknik Kesehatan Kota Palangka Raya, sedangkan FJ saat ini sedang menempuh pendidikan di Sekolah Menengah Kejuruan

Dipublikasikan Oleh : 
(SMK) Farmasi. Berikut hasil wawancara dengan FH dan FJ:

“...usaha yang sudah saya lakukan, saat ini sedang menjalani tes Kak untuk mendaftar kuliah di Poltekes, selain itu saya juga sambil membaca-baca sedikit tentang jurusan kebidanan.” (FH)

“...usaha saya saat ini lebih membaca tentang buku-buku farmasi, jika ada yang kurang paham langsung saya tanyakan ke Guru, Kak. Saya sekarang juga sedang mengembangkan kemampuan dalam

\begin{tabular}{|c|c|c|c|}
\hline Nama & $\begin{array}{c}\text { Jenis } \\
\text { Kelamin }\end{array}$ & $\begin{array}{c}\text { Usia } \\
\text { (Thn } \\
\text { ) }\end{array}$ & Tes RMIB \\
\hline $\mathrm{FH}$ & $\mathrm{Pr}$ & 17 & $\begin{array}{l}\text { Medical } \\
\text { Practical } \\
\text { Scientific }\end{array}$ \\
\hline WR & $\mathrm{Lk}$ & 16 & $\begin{array}{l}\text { Social Service } \\
\text { Clerical } \\
\text { Aesthetic }\end{array}$ \\
\hline $\mathrm{KL}$ & $\mathrm{Lk}$ & 16 & $\begin{array}{l}\text { Mechanical } \\
\text { Outdoor } \\
\text { Personal } \\
\text { Contact }\end{array}$ \\
\hline YA & $\mathrm{Lk}$ & 17 & $\begin{array}{l}\text { Social Service } \\
\text { Literary } \\
\text { Practical }\end{array}$ \\
\hline FJ & Lk & 16 & $\begin{array}{l}\text { Medical } \\
\text { Practical } \\
\text { Mechanical }\end{array}$ \\
\hline HB & $\mathrm{Lk}$ & 15 & $\begin{array}{l}\text { Practical } \\
\text { Mechanical } \\
\text { Scientific } \\
\end{array}$ \\
\hline $\mathrm{MU}$ & $\mathrm{Lk}$ & 16 & $\begin{array}{l}\text { Social Service } \\
\text { Outdoor } \\
\text { Compulational }\end{array}$ \\
\hline SY & $\mathrm{Lk}$ & 16 & $\begin{array}{l}\text { Social Service } \\
\text { Practical } \\
\text { Compulatonal }\end{array}$ \\
\hline AN & $\mathrm{Pr}$ & 18 & $\begin{array}{l}\text { Mechanical } \\
\text { Scientific } \\
\text { Outdoor }\end{array}$ \\
\hline
\end{tabular}

\section{Tabel 1. Hasil tes RMIB}

FH dan FJ melakukan usaha untuk mencapai minat yang diinginkan. FH memiliki tekad yang kuat agar bisa meraih apa yang disenangi sejak lama. FH sangat mengidamkan agar bisa menjadi bidan. FH termotivasi dari bidan yang ada di kampungnya. Sementara FJ juga melakukan usaha pada minat medical. FJ bercerita bahwa awalnya dia tidak berminat dengan sekolah farmasi. FJ sekolah di SMK Farmasi karena tuntutan orangtua. Tapi lama kelamaan FJ menyukai farmasi. FJ juga mendapatkan dukungan dari orangtua dan temanteman di sekolah maupun di LKSA. Hal itu membuatnya menjadi semangat dan termotivasi.

Remaja selanjutnya adalah WR, YA, MU dan SY memiliki perhatian kepada minat yang sama di bidang social service, yaitu membantu atau membimbing orang lain. WR, YA, MU dan SY ingin menjadi Guru, dan keempatnya sudah melakukan usaha agar bisa mencapai minatnya itu. Berikut hasil wawancara dengan WR, YA, MU dan SY:

"...usaha yang sudah saya lakukan adalah belajar di sekolah maupun di LKSA. Sekarang saya sedang mengasah kemampuan untuk mengajar, Kak.” (WR)

“...usaha yang sudah saya lakukan yaitu membekali diri dengan ilmu agama yang didapatkan di sekolah dan di LKSA AlAmin, Kak. Saya juga berupaya untuk mengasah kemampuan dalam hal praktik mengajar dengan baik." (YA)

“...saat ini saya sedang belajar bahasa Arab, Kak. Saya juga berusaha memperluas ilmu dan juga mengasah kemampuan mengajar." (MU)

“...Ayah saya mau mendirikan Pondok Pesantren, Kak. Makanya saat ini saya kadang-kadang praktik mengajar di depan teman-teman LKSA Al-Amin. Paling sering mengajar ngaji, Kak.” (SY)

Saat melakukan wawancara, keempat informan tidak kebingungan menjawab pertanyaan. Hal ini disebabkan karena minat dalam bidang social service sudah diidamkan sejak lama dan saat ini sedang menempuh pendidikan sembari terus mengasah kemampuan.

Remaja berikutnya yaitu KL dan AN yang mempunyai minat pada mechanical. KL dan AN saat ini sedang menempuh pendidikan di SMK Otomotif. KL dan AN memiliki perhatian pada minatnya. Usaha yang telah KL dan AN lakukan adalah selalu mengasah ilmu yang sudah dimilikinya. Berikut hasil wawancara dengan KL dan AN:

“...minat saya dalam bidang mekanik masih saya perdalam, Kak. Kadang- 
kadang saya latihan memodifikasi motor, untuk mengasah kemampuan saya.” (KL)

“...saya selalu mengamati setiap kendaraan yang diservis, Kak. Paling sulit menurut saya adalah bagian kelistrikan pada kendaraan. Saat ini saya sedang magang di bengkel, Kak. Jadi ada kesempatan untuk belajar lebih banyak, dan mengembangkan ilmu perbengkelan lainnya." (AN)

KL dan AN memiliki perhatian pada minat mechanical. Keduanya bersama-sama memperdalam dan mengasah minat yang sudah ada. KL dan AN sebenarnya memiliki beberapa minat, hanya saja satu minat yang dominan pada KL dan AN yaitu minat pada mechanical. Mereka memiliki semangat untuk terus menambah penguasaan dan pengetahuan dalam bidang tersebut.

Terakhir yaitu remaja berinisial HB, yang memiliki minat practical dalam bidang pertanian. HB berkeinginan jika selesai sekolah nanti, HB mengambil jurusan pertanian. Hal ini dikarenakan HB ingin membantu Mbahnya yang mempunyai kebun di daerah Jawa. HB ingin mengembangkan pengetahuannya di dunia pertanian. Berikut kutipan wawancara dengan HB:

“...saya ingin mendalami pelajaranpelajaran tentang tanaman-tanaman, Kak. Saya mempunyai rencana kuliah di jurusan pertanian dan ingin mengembangkan kebun yang dimiliki keluarga saya. Saat ini saya sangat bersemangat memperluas ilmu pengetahuan tentang tanaman, Kak." (HB)

Ketika melakukan wawancara HB menjelaskan dengan lancar mengenai keinginannya menjadi petani, satu-satunya minat yang ingin dicapainya saat ini yaitu menjadi petani, HB memang mempunyai kesukaan dibidang lain seperti mechanical, namun ketika menjawab pertanyaan saat wawancara, HB lebih condong ke dunia pertanian.

Berdasarkan hasil tes minat RMIB, observasi dan wawancara terhadap remaja di LKSA Al-Amin, diketahui bahwa mereka memiliki beberapa minat namun hanya minat tertentu yang dikembangkan. Remaja di LKSA
Al-Amin sudah memiliki rencana ke depan berdasarkan minat yang mereka miliki.

Selain hasil yang ditemukan di atas, dari 9 orang responden di LKSA Al-Amin didapatkan bahwa remaja memiliki berbagai macam minat yang dipengaruhi baik dari kondisi individu maupun lingkungan. Fakta ini sejalan dengan pendapat Crow \& Crow (dalam Abror, 1983) yang mengemukakan bahwa banyak hal yang dapat mempengaruhi minat, baik pengaruh dari individu (internal) maupun lingkungan masyarakat (eksternal).

\section{Faktor Internal}

Dorongan dari dalam diri (internal) merupakan faktor yang berhubungan dengan dorongan fisik, motif, mempertahankan diri dari rasa lapar, rasa takut, rasa sakit dan sebagainya. Jika individu merasa lapar ini akan menimbulkan minat untuk mencari makan. Dari serangkaian jawaban remaja di LKSA Al-Amin terdapat tiga dari sembilan informan yang memiliki minat berdasarkan faktor internal atau faktor dari dalam dirinya. Faktor dorongan dari dalam diri bisa dilihat dari bagian minat pada poin perhatian. Adapun hasil wawancara didapatkan bahwa remaja di LKSA Al-Amin memiliki perhatian dan usaha untuk mencapai minat yang sudah diidamkan sejak lama, ada juga remaja yang ingin mempertahankan minat yang sudah dimiliki, seperti keinginan pada seni ke-Islaman, dan minat menjadi bidan.

Remaja-remaja ini dengan tegas menjelaskan bahwa mereka mempunyai minat atau keinginan yang berbagai macam, tetapi lebih cenderung ingin mencapai minat yang sudah diinginkan sejak lama. Tiga dari sembilan informan tersebut sudah melakukan usaha untuk mengasah atau mengembangkan minat yang telah dimiliki. Mengenai motif internal, penelitian yang dilakukan oleh Etnanta \& Irhandayaningsih (2017) yang menyebutkan adanya hubungan yang positif antara minat baca dengan penggunaan smartphone pada remaja. Dalam penelitian ini diungkap bahwa keinginan remaja dalam mengetahui sesuatu tumbuh dari dalam diri dengan perantara smartphone. Remaja mendapatkan banyak informasi melalui membaca sehingga timbul minat baca.

\section{Faktor Eksternal}

1. Motif Sosial

Motif sosial merupakan faktor yang membangkitkan minat untuk melakukan aktifitas demi memenuhi kebutuhan sosial, 
seperti kebutuhan hunting foto demi memenuhi tugas pameran, dan sebagainya. Pada wawancara didapatkan berbagai jawaban dari para remaja, yaitu terdapat tiga dari sembilan informan memiliki minat karena faktor motif sosial Ketiganya memiliki minat karna faktor sosial. Ketika wawancara dengan mereka, para informan memberikan jawaban seperti, mau menjadi petani karena ingin mengembangkan usaha kebun milik kakeknya. Ada juga yang bercita-cita menjadi ustadz atau guru karena ingin mengembangkan pondok pesantren milik Ayahnya. Adapun informan berikutnya memiliki minat pada bidang farmasi karena tuntutan orangtua. Para remaja ini mempunyai keinginan dan usaha agar minatnya bisa dikembangkan.

2. Faktor Emosional (Perasaan)

Faktor ini dapat memacu minat individu apabila menghasilkan emosi atau perasaan senang. Perasaan ini akan membangkitkan minat dan memperkuat minat yang sudah ada. Di LKSA Al-Amin, didapatkan bahwa tiga dari sembilan remaja memiliki minat berdasarkan faktor emosional. Dua informan memiliki minat pada mechanical dan satu informan mempunyai minat social service. Kedua informan tersebut saat ini menempuh pendidikan di SMK otomotif, sementara satunya menempuh pendidikan di perguruan tinggi. Jawaban wawancara ditemukan ada dua remaja yang memiliki keinginan untuk memperkuat minat yang sudah ada. Salah satu informan sedang magang di bengkel dalam rangka memperdalam dan mengasah ilmu yang didapatkan di sekolah. Informan yang sedang menempuh pendidikan di perguruan tinggi ingin jadi guru, oleh karena itu dia mengasah kemampuan di bangku kuliah dalam rangka mewujudkan minat tersebut.

Mengasah minat dengan cara melakukan aktifitas pada tempat yang mendukung tumbuhnya minat yang diinginkan merupakan langkah yang tepat. Sebab jika tidak demikian, perlahan namun pasti minat terhadap sesuatu bisa berkurang. Hal ini senada dengan penelitian Rizal (2021) yang mengungkap bahwa remaja yang jarang bahkan tidak pernah melaksanakan aktifitas di masjid, akan sulit memiliki minat untuk hadir dalam pengajian ataupun kegiatan keagamaan lainnya.

\section{PENUTUP}

Pada penelitian ini diperoleh kesimpulan bahwa terdapat beragam minat yang dimiliki oleh remaja di LKSA Al-Amin Kota Palangka Raya. Hal ini ditunjukkan oleh hasil tes minat menggunakan alat tes Rothwell Miller Interest Blank (RMIB). Terdapat empat orang yang memiliki kecenderungan pada minat social service, dua orang cenderung pada medical, dua orang mechanical dan terdapat satu orang yang mempunyai minat pada bidang practical.

Penelitian ini juga mengungkap adanya pengaruh motivasi internal dan eksternal yang mendorong remaja di LKSA Al-Amin untuk menguatkan minat yang mereka miliki. Khusus pada motivasi eksternal, motif sosial dan emosional mempunyai peran yang signifikan dalam menumbuhkan minat pada remaja di LKSA Al-Amin.

Rekomendasi bagi penelitian selanjutnya adalah hendaknya dilakukan pengkajian yang lebih mendalam terhadap macam-macam motivasi remaja yang dapat mendorong pada peminatan tertentu. Dengan begitu, diharapkan remaja dapat menentukan pilihan sejak awal lalu mengasah minat tersebut sampai pada level yang tertinggi.

\section{REFERENSI}

Abror, Abd. R. (1983). Psikologi Pendidikan. Tiara Wacana.

Adamson, L. B., Deckner, D. F., \& Bakeman, R. (2010). Early Interests and Joint Engagement in Typical Development, Autism, and Down Syndrome. Journal of autism and developmental disorders, 40(6), 665-676. https://doi.org/10.1007/s10803-009-09141

Ajhuri, K. F. (2019). Psikologi Perkembangan: Pendekatan Sepanjang Rentang Kehidupan. Penebar Media Pustaka.

Akmila, D., Zulkifli, S., Husni, M., \& Helminasari, S. (2019). Analisis Minat Remaja dalam Berorganisasi di Kelurahan Lempake Kota Samarinda. FisiPublik: Jurnal Ilmu Sosial Dan Politik, 4(2), 128135.

https://doi.org/10.24903/fpb.v4i2.749

Desmita. (2013). Psikologi Perkembangan. PT Remaja Rosdakarya.

Diananda, A. (2019). Psikologi Remaja dan Permasalahannya. ISTIGHNA: Jurnal Pendidikan dan Pemikiran Islam, 1(1), 116-133.

https://doi.org/10.33853/istighna.v1i1.20 
Meylani Safar Rini, Ihsan Mz, Desi Erawati Jurnal Bimbingan dan Konseling Ar-Rahman Volume 7, Nomor 2, Tahun 2021 e-ISSN 2477-6300

Dinas Sosial. (t.t.). Data Lembaga Kesejahteraan Sosial Di Palangka Raya. https://dinsos.palangkaraya.go.id/data/dat a-lembaga-kesejahteraan-sosial-dipalangka-raya/

Etnanta, Y. C., \& Irhandayaningsih, A. (2017). Pengaruh Penggunaan Smartphone Terhadap Minat Baca Siswa SMA Negeri 1 Semarang. Jurnal Ilmu Perpustakaan, 6(1), 11

Hurlock, E. B. (1980). Developmental Psychology: A Life-Span Approach (5th ed). McGraw-Hill.

Kemdikbud. (t.t.). KBBI Online. Kementerian Pendidikan dan Kebudayaan RI. https://kbbi.kemdikbud.go.id/entri/minat

Rahmawati, E., \& Rahmah, R. (2016). Hubungan Peran Ayah Terhadap Pemenuhan Tugas Perkembangan Remaja. Jurnal Kebidanan Dan Keperawatan Aisyiyah, 12(2), 173180. https://doi.org/10.31101/jkk.299

Rizal, S. (2021). Minat Remaja Dalam Mengikuti Kajian Keagamaan. Dakwatul Islam: Jurnal Ilmiah Masyarakat Islam, 8(1), 10.

Samsudin, M. (2015). Akhlak Pelajar Perspektif Al-Zarnuji: Telaah Isi Kitab Ta'lim alMuta'allim dan Implementasinya di Pendidikan Kontemporer. Alashriyyah, 1(1), 20-20.

Santrock, J. W. (2006). Life-span development (10th ed). McGraw-Hill.

Sefrina, A. (2013). Deteksi Minat Bakat Anak. Media Pressindo.

Sriastuti, N. P., \& Lasmawan, I. W. (2014). Peningkatan Minat Belajar dan Kemampuan Dasar Kognitif Melalui Penggunaan Media Puzzle Pada Anak Kelompok B TK Dharma Kumara Pedungan Denpasar Tahun Ajaran 2012/2013. 4, 9.

Sugiyono. (2008). Metode Penelitian Pendidikan: (Pendekatan Kuantitatif, Kualitatif dan $R \& D$ ). Alfabeta.

Yuliandari, E. (2020). Tes Rothwell Miller Interest Blank. 16.

Dipublikasikan Oleh :

UPT Publikasi dan Pengelolaan Jurnal

Universitas Islam Kalimantan Muhammad Arsyad Al-Banjari Banjarmasin 